\title{
Traveling with food allergy: What to expect from the airlines?
}

To the Editor,

Food allergy (FA) has a significant impact on patients' and families' quality of life, ${ }^{1}$ and considering that traveling is particularly anxiety provoking for children, ${ }^{2}$ many parents prefer to minimize the risk induced by such activities by avoiding them altogether. ${ }^{3}$

Although some previous studies have reported the occurrence of allergic reactions in airplanes ${ }^{4-6}$ and also the high risks perceived by passengers, data on the preparation of the airlines to deal with FA are strongly limited. ${ }^{7,8}$ The only single study that addressed this topic involved an online questionnaire to five airlines and reported a total lack of response to the survey. Given the results, the authors suggested the use of simulated passengers as an alternative approach for enquiry. ${ }^{9}$ Concerning the time passed since the mentioned study, the public's rising concern about FA, and the new legal provisions regarding the consumer protection, we aimed to evaluate the current receptivity of airlines to the FA issue and to assess their ability to support food-allergic passengers.

An online systematic research was performed based on the worldwide commercial airlines in operation. Cargo, maintenance, military, governmental, and medical emergency airlines were excluded jointly with airlines without active website or contact information. The official websites of airlines were accessed on September 2013 to obtain an email or contact form, and a total of 841 airlines, from 216 countries, were contacted by email and invited to participate in the study, between February and April 2014. Then, an online questionnaire addressing the ability of companies to support passengers with FA was conducted and included 19 questions evaluating the availability of alternative meals by class, flight duration or route, the staff's training to deal with emergencies, and the specific restrictions or recommendations made by the airline for food allergic passengers. The average filling time of the questionnaire was estimated to be 5 minutes, and two reminders were sent during the contact period. Posteriorly, a subsample corresponding to the top 100 airlines, in accordance with World Airlines Awards 2015, was requested to reply to a simulated reservation for a passenger with FA that intends to travel with his 5-year-old food-allergic son and wants to address the availability of special meals on board, the availability of trained staff, and the possibility of carrying their own food and medication onboard. Additionally, the information available on the website of the top 100 airlines was also analyzed, between November and December 2015, using the keywords "food allergy" or "allergy" and searching into the web pages about in-flight meals, special meals, special travel needs, medical conditions, special assistance, and baggage. The study was approved by the ethical committee of the University of Porto, and the informed consent and the confidentiality of data were clearly stated in the emails.

From the 841 airlines invited to participate in the study, the contact failed with 117 , and three refused to participate. Therefore, from the remaining 721 airlines, five contacted us mentioning that they could not provide the requested information, and three completed the survey in the online platform. All the three airlines reported that they have alternative menus for food-allergic passengers, trained staff to deal with emergencies, and that have no restrictions on traveling costumers with FA bringing food or medication onboard.

Concerning to the simulated reservation for a passenger with FA, six of the world top 100 companies reported to have all the available information that they can provide on their website, and 16 answered to the questions. For the availability of menus for food allergies, eight airlines reported to have special menus, five reported no alternatives, and three did not answer to the question. Regarding the crew training, only two airlines reported staff trained for emergencies, and the remaining 14 did not answer to the question. About the carriage of food onboard, 11 airlines reported to allow passengers to carry their own food onboard, one reported that it is not possible, and four did not answer to the question. Concerning the transportation of the Epipen ${ }^{\circledR}$ onboard, nine airlines reported to allow, and seven did not answer. Additionally, eight of the respondent airlines clearly highlighted that they cannot guarantee allergen-free flights, because the risk of crosscontact in the airplane.

Considering the analysis of the world top 100 airlines' websites, we observed that 22 airlines plainly mention special menus for food allergies, 40 make specific medical advices regarding FA, 26 refer the possibility of bring food onboard, and four airlines mention that their staff is trained to manage a food-allergic reaction.

Our results show a high non-response rate for both approaches; however, the proposed passenger simulation was more effective in obtaining answers. The information available on the airlines' website was also indicated by the airlines as a source of information, albeit most of the companies' websites also does not provide complete and accurate information for passengers with FA, about the topics under analysis.

Thus, the results may suggest that some airlines rely on the passengers' behavior to protect themselves, taking into account that only a few of them report management strategies as alternative menus for FA and trained staff to handle emergencies. Then, despite the need to encourage preventive efforts by passengers, protective measures such as availability of injectable epinephrine and staff trained in its proper administration should be taken on all commercial airliners. ${ }^{10}$

This study has some limitations namely, the email and survey were written only in English, and also the customer service/ general email address possibly may not have been directed to the person in charge. Nevertheless, this is the largest study that aimed obtaining international data on the ability of airlines to support passengers with FA and provides new insights regarding the contact approach to those who wish to conduct other studies in this field. 
In conclusion, our study shows that airlines do not provide effective and clear communication about food allergy through their websites or by email contact, which may increase the difficulties on trip planning for a food-allergic patient, and therefore contribute to the withdrawal of travel by plane. It has also impact on clinical practice as a message for providers to educate their patients that airlines are often not equipped to manage FA so they should be vigilant themselves. Our results reinforce the need for better cooperation, awareness, and education of the airlines to the needs of passengers with FA, to ensure the safety of families and increase their confidence in air travel.

$$
\begin{array}{r}
\text { Inês Pádua }{ }^{1} \text { iD } \\
\text { André Moreira }{ }^{2,3,4} \\
\text { Patrícia Padrão }{ }^{1,4} \\
\text { Pedro Moreira }{ }^{1,5} \\
\text { Renata Barros }{ }^{1} \\
\\
{ }^{1} \text { Faculty of Nutrition and Food Sciences, University of Porto, } \\
\text { Porto, Portugal } \\
{ }^{2} \text { Faculty of Medicine, University of Porto, Porto, Portugal } \\
{ }^{3} \text { Centro Hospitalar de São João, Porto, Portugal } \\
{ }^{4} \text { Institute of Public Health, University of Porto, Porto, Portugal } \\
\text { Research Centre in Physical Activity, Health and Leisure, University of } \\
\text { Porto, Porto, Portugal } \\
\text { Email: inespadua@fcna.up.pt }
\end{array}
$$

\section{REFERENCES}

1. Cummings AJ, Knibb RC, King RM, Lucas JS. The psychosocial impact of food allergy and food hypersensitivity in children, adolescents and their families: a review. Allergy. 2010;65:933-945.

2. Avery NJ, King RM, Knight S, Hourihane JO. Assessment of quality of life in children with peanut allergy. Pediatr Allergy Immunol. 2003;14:378-382.

3. Bollinger ME, Dahlquist LM, Mudd K, Sonntag C, Dillinger L, McKenna $\mathrm{K}$. The impact of food allergy on the daily activities of children and their families. Ann Allergy Asthma Immunol. 2006;96:415-421.

4. Greenhawt M, MacGillivray F, Batty G, Said M, Weiss C. International study of risk-mitigating factors and in-flight allergic reactions to peanut and tree nut. J Allergy Clin Immunol Prac. 2013;1:186-194.

5. Sicherer SH, Furlong TJ, DeSimone J, Sampson HA. Self-reported allergic reactions to peanut on commercial airliners. J Allergy Clin Immunol. 1999;104:186-189.

6. Comstock SS, DeMera R, Vega LC, et al. Allergic reactions to peanuts, tree nuts, and seeds aboard commercial airliners. Ann Allergy Asthma Immunol. 2008;101:51-56.

7. Greenhawt MJ, McMorris MS, Furlong TJ. Self-reported allergic reactions to peanut and tree nuts occurring on commercial airlines. J Allergy Clin Immunol. 2009;124:598-599.

8. Leonard SWC, Furlong T, Sicherer S. Food allergies affect vacation planning. J Allergy Clin Immunol. 2009;123:S28.

9. Shehata Y, Sheikh A. Flight anaphylaxis emergencies: lessons gained from attempting a questionnaire pilot study. Prim Care Respir J. 2007;16:321.

10. James JM. Airline snack foods: tension in the peanut gallery. J Allergy Clin Immunol. 1999;104:25-27.

\section{Risk factors for developing food-induced bronchospasm during oral food challenge}

To the Editor,

Prevalence of both asthma and food allergy is increasing in Western Europe. ${ }^{1,2}$ In France, according to recent surveys, the prevalence of asthma is $9.4 \%$ in children and $7 \%$ in adults. ${ }^{3}$ Food allergy proven by oral food challenges (OFCs) affects between 1 and $10 \%$ of the population. ${ }^{4}$ Studies have been considering both disorders as comorbidities under the atopic disease concept. Asthmatic children with food allergy have an increased risk of asthma exacerbation and severe asthma, especially when developing anaphylactic reactions. ${ }^{1,5}$ Each part of the respiratory system (the nose, the larynx, and the lungs) may be involved in food-induced allergic reactions, especially in IgE-mediated allergic reactions, and food allergies play a role in the pathogenesis of respiratory tract symptoms. ${ }^{6}$

Bronchospasm caused by food allergy is a condition that may be elicited by either ingestion or inhalation of food allergens. Little is known about the frequency or the risk factors for food-induced bronchospasm.

The aim of this study was to establish the frequency of bronchospasm during positive OFC and to identify possible risks factors.
We conducted a retrospective study including all consecutive patients aged 5 years and older, with a positive OFC to any food, investigated at the Allergy Unit of the University Hospital of Montpellier, France, from January 2001 to January 2016, without discriminating if they suffered or not from asthma.

Prior to OFC, to conduct a complete allergy work-up and to reach a proper diagnosis, we collected for each patient the clinical history and looked for positive skin prick tests (SPT) and/or serum-specific IgE (ImmunoCAP Phadia, Thermo Fisher Scientific ${ }^{\circledR}$ ). To increase the sensitivity of SPT, skin tests were performed with the standardized extract (if available), as well as with the native food. All in vivo methods followed the EAACI recommendations for OFC. ${ }^{7}$ The cutoff used for positive serum-specific IgE was $0.10 \mathrm{kU} / \mathrm{L}$. To standardize the classification of allergic reactions reported by patients and during OFC, we used Sampson's classification for anaphylaxis. ${ }^{8}$ Adequately trained personnel performed pulmonary function testing (PFT) in each patient, before and after OFC (and if needed and possible, during OFC), through spirometry. Diagnosis of bronchospasm was based on both clinical criteria and PFT results, obtained at the time of the reaction 